Cadernos de Clio, Curitiba, n. ${ }^{\circ} 2,2011$

\title{
A posse de territórios e indivíduos no Novo Mundo
}

\author{
Ana Cláudia Magalhães Pitol ${ }^{l}$
}

Resumo: Este artigo tem por objetivo apresentar a análise de relatos produzidos durante o século XVI sobre as Américas Portuguesa e Espanhola, a fim de verificar a realização do embarque de indígenas para a Europa. Estes deslocamentos evidenciam que a posse da América pelos europeus não se restringiu aos territórios, estendendose também aos grupos humanos. Procurou-se identificar como, sob a ótica européia, os indígenas americanos foram tomados e incorporados a uma nova cultura, mesmo que embarcados por vontade própria. Os principais documentos foram: Os Diários de Colombo (1492-1502); a Relação da viagem do Capitão de Gonneville às Novas Terras das Índias de Binot Palmier de Gonneville (1503-1505); a Historia Verdadera de la Conquista de la Nueva España, de Bernal Díaz del Castillo (1632); o ensaio Dos Canibais (1580), de Montaigne e, Une fête Brésilienne en Rouen (1850) de Ferdinand Denis, que apresenta o manuscrito que descreve a participação dos indígenas brasileiros levados para a França em 1550 na entrada do rei Henrique II na cidade de Rouen.

Palavras-Chave: cativo; práticas da vitória; ameríndios na Europa; exibição de indígenas

\section{Introdução}

Ao nos deparamos com documentos como o manuscrito que descreve a entrada do Rei Henrique II na cidade de Rouen, em 1550,

\footnotetext{
${ }^{1}$ Aluna de Graduação em História na Universidade Federal do Paraná.
} 
no qual estavam presentes cinquenta índios provenientes do Brasil, a curiosidade leva-nos a questionar como foi a trajetória desses personagens e se foram levados como cativos ou por vontade própria. ${ }^{2}$ Sabemos através dos documentos que os destinos destes indígenas uma vez fora de sua terra natal foram diversos: como representantes do exotismo que se descortinava aos olhos do Velho Mundo foram apresentados nas Cortes e levados para serem educados nos moldes europeus. Muitos não resistiram à longa viagem e ao contato morrendo antes da chegada.

Este artigo visa analisar os fragmentos das histórias de alguns desses personagens. Reconstruir suas trajetórias, porém, é, sem dúvida, muito difícil devido à ausência de fontes que possam trazer as perspectivas indígenas do encontro entre Velho e Novo Mundo. Mesmo quando os documentos mostram as vozes dos indígenas seu discurso é filtrado por aquele que o registra e que se considera branco, europeu, ocidental, civilizado, olhando dessa perspectiva para o nativo.

\footnotetext{
${ }^{2}$ Em 1550, na entrada do Rei Henrique II na cidade de Rouen, foram apresentados diversas encenações que tinham por objetivo mostrar ao rei como eram suas posses pelo mundo. No caso brasileiro, neste período, as possessões francesas não iam além de pontos na costa onde era realizado o escambo com os indígenas. Mesmo assim, cinquenta índios brasileiros, misturados a normandos vestidos "à moda brasileira", encenaram como era a vida no Brasil, segundo documentos que descreveram o evento.
} 
Esses embarques demonstram que a posse estabelecida pelos europeus abarcou muito além das terras e bens materiais que os europeus encontraram na América. Os nativos também faziam parte do butim da conquista. Dessa forma, esses deslocamentos de nativos das Américas Portuguesa e Espanhola são encarados como uma das práticas pelas quais os europeus, o grupo que se julga dominador ou superior no contato estabelecido com o outro, demonstravam seu poder, expressavam sua vitória e a dominação dos nativos. Através das viagens os europeus efetuavam a apropriação física e simbólica do "outro" americano. Buscou-se, portanto, analisar relatos produzidos durante o século XVI a fím de verificar as formas como foi exercida a vitória envolvendo portugueses e espanhóis e indígenas de diversas etnias e como, por meio dessas práticas, os grupos vencedores construíram aspectos de sua identidade. Este transporte dos indígenas é entendido como uma prática da vitória, na qual o europeu acredita que dispõe dos indígenas assim como dispõe de qualquer dos bens materiais que encontra onde desembarca (DORÉ, 2009).

\section{Documentos e bibliografia sobre o tema}

As viagens realizadas pelos nativos americanos compõem apenas uma das facetas do encontro entre a Europa e a América a ser 
explorada. O caso de Rouen, apontado na Introdução, destaca um aspecto mais profundo deste contato entre mundos que teve início no século $X V$. O espetáculo visava mostrar ao rei suas posses na América e, como podemos perceber, tais posses abarcavam também os habitantes do território, os indígenas. Embora possa ter sido o mais expressivo no que toca à quantidade de índios transportados, Rouen não foi caso isolado. Desde o primeiro encontro entre europeus e americanos essas viagens tornaram-se frequentes. Apesar de lacunares os documentos que atestam esses deslocamentos indígenas compõem um conjunto considerável, o que por si só já é um indício de que tais viagens foram algo recorrente desde o início dos contatos.

Sabe-se que após o embarque do primeiro indígena, outros foram levados e seus destinos foram vários. Além de Colombo, outros viajantes, ingleses (como John Guy, Cabot, Michael Lok e George Best), franceses (Paulmier de Gonneville e Jacques Cartier) e espanhóis (Hernando De Soto, Cortez e Bernal Díaz) deixaram relatada a ida de indígenas para o Velho Mundo. Mas diversos outros poderiam ser citados.

Não só em relatos de viagem podemos encontrar estes nativos viajantes, como nos mostram os documentos relativos ao já citado espetáculo de Rouen, que, tanto por seu caráter oficial, quanto 
pela encenação da alteridade sem precedentes que ali se realizou, nos legou diversos vestígios, tanto imagéticos como textuais. Além do manuscrito anônimo elaborado para servir de guia para o espetáculo, L'entree du très magnanime très puissant et victorieux roy de France Henry deuxième de ce nom en sa noble cité de Rouen (1550), outros dois relatos, estes impressos, documentam o acontecimento: o de Robert Masselin, L'Entree Du Roy nostre sire en sa ville de Rouen (1550), e o de Robert le Hoy e Jean du Gord, intitulado C'est la dedvction du sumptuex ordre plaisantz Spetacles et magnifiques theatres dresses, et exhibes par les citoiens de Rouen ville Metropolitaine du pays de Normandie (1551). Rouen ecoará ainda no século XIX, na obra de Ferdinand Denis, Une fête brésilienne célébrée à Rouen en 1550, onde o autor descreve os acontecimentos com base no relato de Robert le Hoy e Jean du Gord (DENIS, 1944). Doze anos depois do espetáculo, Montaigne encontra-se com alguns indígenas nesta cidade, e em 1580 no seu ensaio, "Dos Canibais", descreve o diálogo que travou com um dos indígenas ali presentes (MONTAIGNE, 1994).

Porém, muito antes dos tupinambás de Rouen terem pisado em solo francês, um outro indígena, carijó, já havia realizado a travessia do Atlântico e aportado na França. A Relação da viagem do Capitão de Gonneville às Novas Terras das Índias (1503-1505) 
relata a viagem deste comerciante que esteve no início do século XVI em terras brasileiras. Entrando em contato com os carijós passou alguns meses no Brasil e no retorno levou consigo dois índios, Esomericq, filho do cacique carijó Arosca, e Namoa. Tentou também capturar dois tupinambás que, no entanto, conseguiram fugir antes da partida (PERRONE-MOISÉS, 1992).

Obviamente não só os franceses levaram indígenas brasileiros para a Europa. Quanto aos portugueses, conforme aponta Arinos, as cartas de doação das capitanias faziam menção à possibilidade de entrada de nativos brasileiros em Portugal. Os donatários poderiam mandar 24 escravos índios a cada ano, livres de direitos de entrada. Esse envio só foi proibido em 1570, período em que, segundo o historiador, essa exportação já devia ser quase nula (FRANCO, 1976: 36-37).

Em terras espanholas, como já mencionado, os embarques se iniciaram após o primeiro contato, como fica explícito nos Diários das viagens de Cristovão Colombo (1492-1502). Esses documentos relatam as viagens do navegador realizadas no período de 1492 1502. Desde a primeira ele manifestou a vontade de levar nativos

para a Europa a fim de que pudessem aprender o espanhol, e realmente efetiva o desejo nesta viagem e nas posteriores (COLOMBO, 1947). Outro espanhol que também deixou registrados 
o cativeiro e o embarque de indígenas para a Europa foi Bernal Díaz de Castillo, em Historia Verdadera de la Conquista Española (1632). Ao narrar as três expedições espanholas ao Yucatán das quais afirma ter participado - a de Francisco Hernández de Córdoba, em 1517; a de Juan de Grijalva, em 1518 e, por fim, a de Cortés, em 1519 - Bernal Díaz nos permite visualizar a existência desses cativos indígenas, como se efetivava a posse sobre eles e sua utilização (CASTILLO, 1960).

Existiam muitas diferenças entre os europeus que aportavam na América e elas se manifestavam na maneira através da qual tomava posse das terras e bens encontrados. Segundo Patrícia Seed, o domínio colonial dependia de práticas cerimoniais que precediam ou sucediam a conquista militar (SEED, 1999). Nos documentos que descrevem estas cerimônias não são explicadas as razões das ações efetuadas para a tomada de posse. Elas baseavam-se em discursos familiares que poderiam ser entendidos pelos seus compatriotas daqueles que as realizavam, mas seu significado nem sempre era óbvio para os outros europeus. A autora busca entender porque estas convicções pareceram razoáveis para os membros de um grupo e não para outros grupos. A própria maneira como cada língua exprime a idéia de "posse", aponta para diferenças entre o que cada grupo entendia por possuir e como essa posse podia ou não ser sancionada. 
Porém, embora existissem diferenças entre os europeus quanto as formas de legitimar a posse dos territórios, um aspecto é recorrente: ela sempre abarcava os grupos humanos que habitavam os territórios.

Para entender a forma através da qual se realizava $o$ processo de posse é de extrema importância a interpretação de Stephen Greenblatt em Possessões Maravilhosas. Em sua discussão sobre a utilização das práticas representacionais européias na efetivação da posse dos territórios do Novo Mundo o autor aponta algumas ações empregadas neste sentido. Vestidos com novas roupas, batizados, e aprendendo uma nova língua, os nativos, na ótica européia, perdiam sua condição de índio e tornavam-se civilizados (GREENBLATT, 1996).

A posse desses seres humanos, semelhante a que se realizava em relação a um objeto ou um animal, é observada pela mesma ótica através da qual a historiadora Andréa Doré observa os conflitos entre portugueses e holandeses no século XVII, e denomina práticas da vitória. Nesta perspectiva entende-se que:

“o exercício da vitória se desdobra em diferentes práticas de punição dos grupos derrotados, assim como em formas de incorporação de elementos desses grupos pelos vencedores e que foram realizadas durante a expansão portuguesa, tenham sido elas protagonizadas ou não por portugueses. Em outras palavras, verificam-se práticas da vitória com 
Cadernos de Clio, Curitiba, n. ${ }^{0}$ 2, 2011

diferentes significações materiais e simbólicas." (DORÉ, 2009: 212)

Dessa maneira, coloca-se em evidência que ao tratar de dois grupos antagônicos, europeus e indígenas, estes não estão sendo apontados como grupos homogêneos. (esta última frase não acrescenta nada ao texto, nem à análise da fonte) Quanto aos europeus, apesar de suas diversas origens, existiam vários aspectos em comum que devem ser levados em conta. Diante da extrema alteridade dos ameríndios, os europeus reconheciam um "outro" diferente dos seus companheiros e também dos seus inimigos. Tanto católicos quanto protestantes, os europeus sentiram-se no direito de se apropriar dos indígenas. Essa apropriação, porém, não precisava se concretizar através da escravização, ou pelo menos, não somente. Os conquistadores sentiram-se imbuídos da missão de transformar o "outro" e o mundo em que vivia e isso se efetuou de diversas formas, desde a destruição de impérios e seu ajuste às necessidades européias, até a catequização. ${ }^{3}$ Nesse sentido, também os embarques dos nativos americanos para a Europa são demonstrativos desse

3 De acordo com Angel Rama a consciência racionalizadora dos espanhóis pretendia não somente organizar os homens dentro do espaço, mas também moldálos com destino a um futuro em obediência as exigências colonizadoras. Em relação à construção das cidades no Novo Mundo, o autor explica que as novas terras abriam a possibilidade de se iniciar uma empresa que não era uma mera transposição do passado e sim a realização de um novo período. Aqui poderiam estabelecer a ordem que não era possível nas cidades da Metrópole (RAMA,1985).

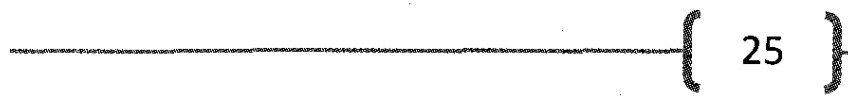


processo. Não podemos descartar a hipótese de que muitos podem ter ido por vontade própria, no entanto, não podiam imaginar o que os esperava do outro lado do Atlântico, e essa vontade não elimina o uso que foi feito deles.

Da mesma forma, os grupos indígenas com os quais os europeus entraram em contato também não eram homogêneos. Todas estas diferenças nos alertam para o fato de que quando colocados esses grupos como vencedores ou vencidos, não se pode fixar tais posições, sem que tenham se alterado ao longo do tempo. Nos conflitos colocavam-se em jogo interesses europeus e também indígenas. Tendo esta reflexão em mente ao analisar os documentos, buscou-se entender de que forma os europeus, ao julgarem-se vencedores nos conflitos com os indígenas, explicitavam sua vitória, punindo-os ou incorporando-os, sem que uma ação exclua a outra.

Neste contexto também são levados em consideração os debates suscitados pela radical diferença encontrada no continente americano e que fizeram parte dos conflitos apresentados pelas fontes, legitimando-os ou não. Tais debates foram pautados por questões morais, religiosas e econômicas. Nos países ibéricos, Igreja e Coroa caminhavam juntas no processo de expansão, o que Greenblatt classifica como imperialismo cristão, viabilizado pela instituição do padroado régio (GREENBLATT, 1996: 96-97). No 
caso de Portugal, a religião foi mesmo um dos motores da expansão (THOMAZ, 1994). Para as Coroas portuguesa e espanhola, era necessário conciliar suas necessidades econômicas e a ganância dos colonos com as questões teológicas e morais, uma vez que o que concedia legitimidade à posse dos territórios americanos era o compromisso com a evangelização dos pagãos. ${ }^{4}$

\section{A realização da posse e a utilização dos indígenas capturados}

A fonte principal dos indígenas que foram levados para a Europa foram os conflitos ocorridos desde o primeiro momento, nos quais eram feitos prisioneiros de ambos os lados, europeu e ameríndio. Mas a violência não era necessária para que o ritual da vitória, expresso pelo transporte dos nativos, se consumasse. Como a Relação de Binot Paulmier de Gonneville apresenta, houve casos em que a viagem em direção à Europa foi um desejo do indígena. A expedição de Gonneville, realizada entre 1503 e 1505, alcançou a costa brasileira na região do atual Estado de Santa Catarina e entrou em contato com os índios carijós. Ao que tudo indica o contato foi muito pacífico e pode-se perceber que a ideia de levar nativos das

\footnotetext{
${ }^{4}$ Houve uma preocupação real das Coroas ibéricas com a causa indígena, apesar disto não ter tido eficácia junto aos colonos. No entanto, mesmo que não tivesse efeito prático, esta preocupação não pode ser descartada, ou encarada como um cinismo dos reis ibéricos.
} 
novas terras era um costume já estabelecido, conforme lê-se no relato:

"porque é costume daqueles que chegam às novas terras das Índias levarem delas à Cristandade alguns índios, tanto se fez, com tal gentileza, que o dito chefe Arosca consentiu que um de seus jovens, o qual se dava bem com os do navio, viesse à Cristandade, já que se prometia ao pai e ao filho trazê-lo de volta dentro de vinte luas ao mais tardar; pois assim eles contavam os meses." (PERRONE-MOISÉS, 1992: 24)

Um aspecto importante pode ser ressaltado na história de Essomericq, o carijó levado para a França, e colocado em contraposição a outros documentos. Conforme aponta Leyla PerroneMosés, na análise da Relação de Gonneville, a etnia de Essomericq explicaria porque ele e seu pai estavam convencidos da conveniência da viagem. Os grupos guaranis, ou guaranizados, como eram os carijós, centravam sua cultura na busca da "terra sem mal" e assim a viagem era algo para o qual estavam pré-dispostos (PERRONEMOISÉS, 1992: 161).

Como já afirmado, e demonstrado por esta característica dos indígenas carijós, os grupos em contato possuíam especificidades que devem ser levadas em consideração. Existem elementos substanciais que nos permitem colocar europeus e indígenas em contraposição, porém sempre se deve ponderar suas diferenças internas. Além disso, 
as posições que esses grupos assumem nos conflitos não foram fixas. Dessa forma, nesta pesquisa, "o que se quer enfatizar é a alternância nessas categorias e a forma como as práticas que envolvem a comemoração da vitória, a punição dos que são vencidos ou a apropriação de elementos dos grupos subjugados se sucedem" (DORÉ, 2009: 201).

A viagem consentida de Essomericq foi uma vitória para os franceses ansiosos por levar naturais da terra à Cristandade ou para os índios? Estes foram convencidos pelos europeus de que aos que fossem com eles "ensinariam a artilharia; o que eles desejavam intensamente, para poderem dominar seus inimigos: como também a fazer espelhos, facas, machados e tudo o que viam e admiravam dos cristãos; o que era prometer-lhes tanto como prometer a um cristão ouro, prata e pedrarias, ou ensinar-lhe a pedra filosofal" (PERRONEMOISÉS, 1992: 24). Estas razões, aliadas às religiosas, indicam que algumas dessas viagens podem mesmo ter sido motivadas pelos interesses indígenas despertados no encontro com os europeus.

Porém, é preciso considerar quem produziu o documento em questão: a Relação foi apresentada por Gonneville no retorno dos navios franceses a Rouen, "conforme requerido pela gente do Rei" (PERRONE-MOISÉS, 1992: 15). Assim os interesses indígenas pelas maravilhas européias podem ser fruto da própria presunção 
européia de que possuíam tudo aquilo de mais interessante e necessário à vida e, que era natural aos carijós, de tudo desprovidos, que se interessassem por isso. Dessa forma, até mesmo o discurso que traduz o desejo indígena pode se referir ao orgulho europeu que se expressava ante o encontro com os americanos.

Em Writing captivity in the Early Modern Atlantic, Lisa Voigt aponta que os relatos de europeus cativos em outros continentes concediam a seus autores privilégios e autoridade quando retornavam a sua terra natal. Isso ocorria em razão do desejo de obter testemunhos oculares das novas terras para estender o domínio territorial e comercial nestes locais (VOIGT, 2009: 1). No entanto, quanto aos índios que são o objeto desta pesquisa, não existem relatos. Poucos são os documentos que apresentam a voz do indígena e os que o fazem a apresentam de forma filtrada. Porém, se não deixaram relatos, os indígenas eram os próprios relatos. Seus corpos e sua língua eram a expressão da diferença cultural e do exotismo do Novo Mundo.

Ao encontrar-se com alguns indígenas brasileiros levados para a cidade de Rouen, o famoso filósofo Montaigne pôde investigar as percepções que tiveram da França. De acordo com Montaigne o diálogo, embora longo, foi dificultado por seu intérprete. O filósofo 
conta que alguém perguntou aos nativos o que pensavam da cidade e eles responderam:

\begin{abstract}
"que lhes parecia estranho tão grande número de homens de alta estatura e barba na cara, robustos e armados e que se achavam junto do rei (provavelmente se referiam aos suiços da guarda) se sujeitassem em obedecer a uma criança e que fora mais natural se escolhessem um deles para o comando. Em segundo lugar, observaram que há entre nós gente bem alimentada, gozando as comodidades da vida, enquanto metades de homens emagrecidos, esfaimados, miseráveis mendiga às portas dos outros (...); e acham extraordinário que essas metades de homens suportem tanta injustiça sem se revoltarem e incendiarem as casas dos demais." (MONTAIGNE, 1994: 103)
\end{abstract}

$\mathrm{Na}$ verdade, ainda que os índios tenham mesmo feito tais observações, elas tem um lugar muito bem definido no pensamento de Montaigne: a crítica do filósofo a sua própria sociedade. Por essa razão, ele lamenta que os indígenas tenham se deixado "tentar pela novidade" e trocado sua terra e seu povo pela Europa.

A história de Essomericq difere, portanto da de outros índios encontrados na Europa, colocando em questão os interesses indígenas nestas viagens. $\mathrm{Na}$ maioria dos documentos este interesse não é expresso, deixando implícita a possibilidade de que foram tomados à força. No entanto, em outros momentos o próprio interesse indígena foi gerado por um ato de violência, como fica 
explícito no Diário de Colombo. Em 12 de novembro de 1492, Colombo decide "tomar algunas personas" e levá-las à Espanha com o objetivo de que aprendessem o espanhol para que quando voltassem pudessem ser "lenguas de los cristianos" (COLOMBO, 1947: 59). Até este momento já haviam sido aprisionados alguns índios, e desta vez são trazidas sete mulheres e três crianças. Posteriormente, o navegador escreve: "Esta noche vino a bordo en una almadía el marido de una de estas mujeres y padre de tres fijos, un macho y dos fembras, y dijo que yo le dejase venir con ellos, y a mí me aplogó mucho, y quedan agora todos consolados con el que deben todos ser parientes, y él es ya hombre de cuarenta y cinco años" (COLOMBO, 1947: 60-61).

Através dos documentos aqui utilizados podemos perceber uma certa recorrência quanto às formas através das quais a posse sobre esses seres humanos se realizava: o batismo, a troca das vestes nativas pelas européias e a aprendizagem das línguas dos conquistadores. O cancelamento das identidades indígenas e sua substituição através do batismo foi um processo que ocorreu tanto com os novos territórios, e a natureza diversa que eles encerravam, como com os indígenas aprisionados por europeus. Na História de la Conquista de la Nueva España, de Bernal Díaz de Castillo são descritos diversos confrontos com os povos nativos que rendem 
cativos, que são batizados e passam a seguir viagem com os espanhóis. $\mathrm{O}$ autor não se preocupa em registrar os nomes originais de Júlian e Melchor, os nativos aprisionados no conflito com os espanhóis no Yucatán e batizados (CASTILLO, 1960: 6).

O próprio Essomericq não deixou de ser batizado. Durante a viagem à França, ele e o outro carijó que o acompanhou na travessia do Atlântico adoeceram gravemente, e nesta situação os demais embarcados no navio discutiram sobre a possibilidade ou não do batismo. Segundo a Relação, foi proposto que não batizassem os indígenas, pois estes não poderiam entender o sacramento que lhes era administrado. O companheiro de Esssomericq faleceu e este acontecimento fez com que os franceses chegassem à conclusão de que era melhor batizá-lo, pois antes receber o batismo sem entendêlo do que ser condenado eternamente em caso de morte (PERRONEMOISÉS, 1992: 90). Neste caso se questiona a percepção do indígena quanto ao sacramento que lhe é imposto, já na História de Bernal Díaz não há sinal deste questionamento.

O batismo pode ser tomado como o primeiro passo da posse. Com ele coloca-se em marcha todo um processo: a cristianização. Esta, por sua vez, transcendia os limites do religioso, pois portava consigo a própria civilização. Isto independia da fé do conquistador, 
pois se para católicos os protestantes eram bárbaros e vice-versa, cada um acreditava no potencial civilizatório de sua religião.

Logo após o batismo era comum que os nativos recebessem roupas à moda européia. Dessa forma, um verniz de civilização cobria o indígena. Os europeus atribuíam um poder de transformação às roupas, como se estas pudessem realmente transformar a identidade nativa, assim como muitas vezes se percebe que o batismo era tido como um ato que por si mesmo convertia os batizados à nova fé.

O que aconteceu com o índio Melchor apresenta um quadro do que significavam as novas vestimentas para os que eram forçados a usá-las e o espanto europeu quando estas eram negadas. Aproveitando-se de um descuido espanhol, Melchor "foi-se com o povo de Tobasco e sucedeu que um dia antes deixou as roupas espanholas que the tinham sido dadas suspensas no bosque das palmeiras" (CASTILLO, 1960: 74).

Uma das grandes motivações para o rapto dos índios foi a necessidade de encontrar intérpretes. Inicialmente a comunicação se deu através de gestos e sinais e, no relato desses diálogos, fica patente que esta comunicação era extremamente defeituosa. Porém, na maioria das vezes os indígenas sempre dizem aquilo que os europeus esperam ouvir. Nos diários de Colombo, os diálogos e as 
falas indígenas não passam de suposições criadas a partir de gestos e a partir desses "diálogos" o navegador chega a grandes conclusões. Em um trecho do Diário da Primeira Viagem refere-se aos habitantes das terras a que chegou:

"Ellos deben ser buenos servidores y de buen ingenio, que veo que muy presto dicen todo lo queles decía, y creo que ligeramente se harían cristianos; que me pareció que ninguna secta tenían. Yo, placiendo a Nuestro Señor, levaré de aquí al tiempo de mi partida seis a V. A. para que deprendan fablar." (COLOMBO, 1947: 33)

Obviamente, os índios sabiam falar, ainda que não fosse a mesma língua de Colombo. A primeira idéia foi a de fazer com que os nativos aprendessem a língua espanhola, e não o contrário. Já nos Diários de Colombo, e confirmado em documentos posteriores, fica claro que o problema linguístico criado então não podia ser resolvido de outra forma que não utilizando intérpretes. Assim, a aprendizagem das línguas européias completava a transformação do indígena e a posse.

Uma vez tomada a posse é preciso se perguntar qual a utilização dada a esses seres humanos. Na América, sem os intérpretes a conquista teria sido impossível, embora saibamos que os serviços prestados pelos indígenas foram além da simples tradução. Uma vez transportados para a Europa os indígenas serviram a outros 
fins, que podemos classificar em duas categorias: o serviço e a exibição. Sem que um excluísse o outro, esses foram os destinos mais frequentes desses nativos, ainda que seja preciso afirmar que existem algumas trajetórias individuais que complexificam esse panorama, como é o caso de Essomericq.

No caso de Rouen, já apontado, os indígenas foram "importados do país" para exibição. Juntamente com os nativos foram trazidos diversos tipos de animais e também foram dispostas no cenário diversas árvores imitando as existentes no Brasil. Buscouse deixar o cenário e a encenação o mais próximos da realidade e por fim o autor afirma que vários franceses que já haviam estado no Brasil "atestaram de boa fé que o efeito da figuração procedente era o simulacro certo da verdade" (DENIS, 1944: 22).

De acordo com Perrone-Moisés, na França, em meados do século, "ter índios brasileiros em casa, como valetes, era uma moda já transformada em hábito" (PERRONE-MOISÉS, 1992: 168). O otimismo da autora até o presente momento não se justifica através dos documentos, porém pode-se perceber que existia o envio de indígenas para prestarem serviços na Europa. Nas cartas-forais dadas pela Coroa Portuguesa aos capitães donatários, por exemplo, como já comentado, era estabelecido um limite para a exportação de nativos. Segundo o documento, o capitão tem direito a "resgatar escravos em 
número indeterminado, podendo enviar a cada ano 39 para Lisboa (e não para outra parte) e dispor deles livremente, sem pagar imposto algum; e além daqueles quanto mais houver para marinheiros e grumetes de seus navios" (CASTRO, 1968: 47). ${ }^{5}$

Como pode-se perceber, no caso de Colombo, não foi necessária nenhuma ordem ou regulamentação da Coroa para que o navegador se sentisse autorizado a levar indígenas para a Espanha. As capturas foram motivadas principalmente pela busca de intérpretes, comportamento que se tornou rotineiro nas expedições espanholas que se seguiram. Porém, mesmo antes de atravessarem o oceano os nativos são utilizados prestando informações e como guias em terra.

\section{Conclusões}

Como este trabalho procurou esclarecer, a posse européia da América estendeu-se a seus habitantes e isto se manifestou através do embarque destes para o Velho Mundo. Embora esparsos no tempo e no espaço estes embarques foram freqüentes, como verifica-se através da leitura dos documentos aqui apresentados. O que se coloca em questão quanto a estas transferências indígenas é o cativeiro

\footnotetext{
${ }^{5}$ Afonso Arinos se refere as cartas-forais, e aponta uma quantidade menor de indígenas a serem levados. No entanto, não é possível saber se o autor se refere a esse documento aqui utilizado especificamente.
} 
iniciado a partir do primeiro contato e a utilização destes seres humanos, aprisionados não só fisicamente como também simbolicamente, uma vez que, por metonímia, o aprisionamento de um indígena simbolizaria a posse de todo o seu grupo.

Mesmo diante de casos como o do carijó Essomericq, que embarcou por vontade própria, é necessário ponderar que seu interesse não anula o interesse francês. Batizado no navio,recebeu o nome do capitão Gonneville e ao que tudo indica passou a ser tratado como um filho. Posteriormente, ele se casou e constituiu uma família. Para os olhos europeus, Essomericq atravessou a fronteira que separava seu grupo dos europeus, passando a viver como um cristão civilizado. Porém algumas questões são suscitadas por essa história. Em primeiro lugar, Essomericq deveria retornar em vinte luas, e não o fez. Segundo a pesquisa realizada por Perrone-Moisés, ele nunca mais pisou em terras brasileiras. Porque não houve o retorno? Teria sido porque Essomericq não quis, ou não teve condições? E Gonneville, que havia feito a promessa tanto ao pai quanto ao filho, porque não a cumpriu? Os documentos apresentados aqui não permitem responder a essas questões, mas elas não deixam de ser oportunas para o alcance dos objetivos deste trabalho. Mesmo motivada por razões religiosas dos carijós que, por isso, estavam pré- 
dispostos para a viagem, esta só foi permitida porque houve a promessa do retorno.

Não se pretende aqui escrever uma história, na qual os indígenas americanos se submeteram sem reação, assistindo passivos a todas as ações européias em seu meio. A história do índio carijó nos leva a refletir que, fossem suas motivações as religiosas, ou fomentadas pelo interesse em aprender coisas úteis a seu povo, ele usou a viagem a seu favor. No entanto, isso não anula o fato de que aqueles que o levaram também fizeram o mesmo e como situações semelhantes a de Essomericq foram pouco documentadas, ou poucos foram os vestígios que nos sobraram, pode-se acreditar que essas travessias atlânticas indígenas foram muito mais uma expressão das vontades européias de possuir.

\section{Fontes}

Carta - foral. In: CASTRO, Therezinha de. História Documental do Brasil. Rio de Janeiro: Record, 1968.

CASTILLO, Bernal Diaz del. Historia de la Conquista de la Nueva España. México: Editorial Porrua, 1960.

COLOMBO, Cristovão. Los cuatro viajes del Almirante y su testamiento. Buenos Aires: Espasa - Calpe Argentina, 1947. 
MASSELIN, Robert e GORD, Jean du. "Suntuosa Entrada". In: DENIS, Ferdinand. Uma festa brasileira. Rio de Janeiro: EPASA, 1944

MONTAIGNE, Michel de. "Dos Canibais". In: Ensaios. São Paulo: Abril Cultural, 1994.

Relação da viagem do Capitão de Gonneville às Novas Terras das Índias. In: PERRONE-MOISÉS, Leyla. Vinte Luas. Viagem de Paulmier de Gonneville o Brasil: 1503-1505. São Paulo: Companhia das Letras, 1992.

\section{Bibliografia}

BELLUZO, Ana Maria de Moraes (org). "O indio brasileiro na Europa". In: O Brasil dos viajantes. O imaginário do Novo Mundo. Vol. 1. São Paulo: Fundação Odebrecht/ Edição Metalivros, 1994.

DENIS, Ferdinand. Uma festa brasileira. Rio de Janeiro: EPASA, 1944.

DORÉ, Andréa. "Charles Boxer, novas perguntas e os butins de guerra nos espaços portugueses no século XVII’. In: VAINFAS, Ronaldo e MONTEIRO, Rodrigo B. (orgs.). Império de várias faces. Relações de poder no mundo ibérico da Época Moderna. São Paulo: Alameda, 2009, p. 195-216. 
FRANCO, Afonso Arinos de Melo. "Viagens de índios brasileiros à Europa". In: $O$ indio brasileiro e a Revolução francesa: as origens brasileiras da teoria da bondade natural. Rio de Janeiro: José Olympio, 1976.

GREENBLATT, S. Possessões Maravilhosas. O Deslumbramento do Novo Mundo. São Paulo: Edusp, 1996.

HANSEN, João Adolfo. “A servidão natural do selvagem e a guerra justa contra o bárbaro. In: NOVAES, Adauto (org.). A descoberta do homem e do mundo. MINC Funarte/ Cia. Das Letras, 1998.

LESTRINGANT, F. "O Brasil de Montaigne". In: Revista de Antropologia, São Paulo, USP, 2006, v. 49, $\mathrm{n}^{\circ}$ 2. Acesso em www.scielo.br, em 09 de fevereiro de 2010.

MONTEIRO, John Manuel. "As populações indígenas do litoral brasileiro no século XVI: transformação e resistência”. In: DIAS, Jill (org.). Brasil nas vésperas do mundo moderno. Lisboa: Comissão Nacional para as Comemorações dos Descobrimentos Portugueses, 1992.

PERRONE-MOISÉS, Leyla. Vinte Luas. Viagem de Paulmier de Gonneville o Brasil: 1503-1505. São Paulo: Companhia das Letras, 1992.

RAMA, Angel. "A cidade ordenada". In: - A cidade das letras.

Rio de Janeiro: Brasiliense, 1985. 
Cadernos de Clio, Curitiba, n. $^{\circ}$ 2, 2011

SEED, Patrícia. Cerimônias de Posse na conquista européia do Novo Mundo (1492-1640). São Paulo: Editora UNESP, 1999.

THOMAZ, Luís Filipe. "Expansão portuguesa e expansão européia reflexões em torno dos Descobrimentos". In: De Ceuta a Timor. Difel, 1994.

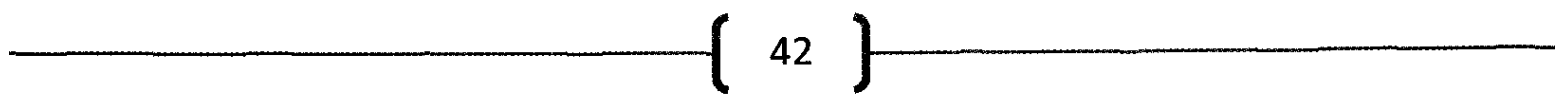

